\title{
UROPATHOGENIC PROPERTIES OF ESCHERICHIA COLI IN RECURRENT URINARY-TRACT INFECTION
}

\author{
Heather J. L. Brooks*, F. O’Grady ${ }^{\dagger}$, M. Anne McSherry and W. R. \\ CATtell \\ Department of Medical Microbiology and Department of Nephrology, \\ St Bartholomew's Hospital, London ECIA $7 B E$
}

ESCHERICHIA COLI is the pathogen most commonly isolated in urinarytract infections (UTI). It is thought that $E$. coli from the gut colonise the periurethral area, extend into the anterior urethra and are introduced into the bladder during micturition. Imperfections in the host defence mechanisms allow bacteria to multiply in the bladder urine and, in some cases, to cause an ascending infection of the kidney (O'Grady et al., 1970).

Unless urinary-tract infection differs from infection elsewhere in the body it is likely that some strains of $E$. coli possess properties that enable them to overcome host defences more easily. Numerous reports have examined whether certain serotypes of $E$. coli are more common in UTI simply because they are more common in the faeces or because they possess specific uropathogenic properties. The properties that might be implicated in the pathogenesis of UTI include: (1) the ability to colonise the urinary tract by the production of mucinase that enables the organisms to reach the uroepithelium, or the possession of fimbriae that allow adhesion to the mucosal surface; (2) preferential nutritional requirements for substances present in urine or relative resistance to urinary inhibitors such as urea or low $\mathrm{pH}$; (3) resistance to phagocytosis and the serum bactericidal system; (4) the elaboration of toxins.

We studied several properties that may influence the pathogenicity of $E$. coli strains and compared their occurrence in strains isolated from (i) the urine of patients with UTI, (ii) the urethral meatus of nephrourological patients without current UTI and (iii) the urethral meatus of normal subjects.

\section{MATERIALS AND METHODS}

\section{Subjects}

One hundred and sixty seven patients and 28 controls were studied. The patients were referred to the Nephrourological Clinic at St Bartholomew's Hospital because of known or suspected UTI; all had been followed for at least 3 months. Intravenous pyelograms were routinely performed and, where necessary, residual urine volumes were measured by the

Present addresses: * Department of Microbiology and Genetics, Massey University, Palmerston North, New Zealand.

$\nmid$ Department of Microbiology, University Hospital, Queen's Medical Centre, Nottingham NG7 2UH. 
$\mathrm{I}^{131}$-hippuran method (Shand et al., 1968). The patients were divided into two groups: (A) abacteriuric patients (62) remained free from infection with $E$. coli during the study. Nine patients were asymptomatic throughout; 53 had symptoms of frequency or dysuria or both, and were described as suffering from the "urethral syndrome"; (B) bacteriuric patients (105) had at least one episode of $E$. coli bacteriuria, i.e., two consecutive urine specimens contained $>10^{5}$ bacteria $/ \mathrm{ml}$. They were subdivided according to the presence or absence of radiological abnormalities. The control group consisted of 28 healthy female laboratory workers with no history of UTI; none had symptoms of UTI or was taking antibiotics.

\section{Collection of specimens}

Periurethral swabs and urine specimens were collected and cultured as described by Cattell $e t$ al. (1974).

\section{Identification of strains}

Strains were identified as E. coli according to Edwards and Ewing (1972); they were maintained in nutrient-agar stabs at $4^{\circ} \mathrm{C}$.

\section{Sources of strains}

Bladder urine strains were isolated from mid-stream specimens of urine from the 105 patients with bacteriuria; one isolate from each patient was randomly selected. Fifteen upper tract strains were from ureteric urine specimens from five male and 10 female patients undergoing localisation tests by the method of Stamey et al. (1965); two strains were isolated from the renal tissue of an excised kidney and two were from renal cálculi from separate patients. Twenty nine lower tract strains were from seven male and 22 female patients undergoing localisation tests; the ureteric urine of these patients was sterile.

Periurethral strains. One hundred and fifty six strains were isolated from periurethral swabs. Forty three strains were from bacteriuric patients between episodes of bacteriuria; the patients were abacteriuric for at least 6 weeks before and 6 weeks after the periurethral strain was isolated. None was taking antibiotics during this period. Nine strains were thought to give rise to infection in that an episode of bacteriuria before or after isolation of the periurethral strain was due to an $E$. coli strain of the same serotype. Sixty eight strains were from abacteriuric patients; 58 were from patients with the "urethral syndrome" and 10 strains were from abacteriuric and asymptomatic patients. Forty five strains were from normal subjects.

\section{Studies of uropathogenic properties}

$O$ and $H$ serotyping. O-serotypes were determined with a set of $150 \mathrm{O}$-antisera (Bettelheim and Taylor, 1969). Motile strains were typed with $52 \mathrm{H}$-antisera (Chandler and Bettelheim, 1974).

$K$ antigen was estimated quantitatively by the method of Glynn and Howard (1970).

Serum sensitivity. Sensitivity to the bactericidal activity of normal human serum was measured by the method of Taylor, Roberts and Gower (1972) except that viable counts were determined by the method of Miles, Misra and Irwin (1938). Serum was collected from four healthy volunteers with no previous history of UTI.

Haemolysin production. "Solid" haemolysin production on blood-agar layer plates and 'liquid' haemolysin productions in isotonic peptone water were determined by the method of Cooke (1968).

Fimbriation. The presence of fimbriae was detected by the methods of Duguid et al. (1955) and Duguid (1968).

Fermentation tests. Strains were incubated for up to one week in sucrose, salicin and dulcitol peptone-water sugars (Oxoid) and examined for acid production on days 1, 2, 3, 4, 5 and 7.

Sensitivity to serine, spermine and urea. Minimum inhibitory concentrations (MICs) of DL 
serine, spermine and urea were determined with the minimal medium of Davis and Mingioli (1950) solidified with $1 \%$ agarose (Miles Serevac) for all strains at $p \mathrm{H} 7.2$ and for randomly selected strains at $p \mathrm{H} 5.5$ and 6.0. Twofold dilutions of serine and spermine were incorporated in the plates to give final concentrations of $1-1024 \mu \mathrm{g} / \mathrm{ml}$ and $32-512 \mu \mathrm{g} / \mathrm{ml}$ respectively. Urea was tested at concentrations of $0.5-0.6 \%$ in $0.5 \%$ steps. Plates were inoculated with $0.001 \mathrm{ml}$ of an overnight broth culture diluted 100 -fold $\left(10^{2}-10^{3}\right.$ organisms) by a multipoint inoculator (Denley Instruments Ltd). The MIC was the lowest concentration that limited growth to $<5$ colonies or a barely discernible haze of growth after overnight incubation at $37^{\circ} \mathrm{C}$.

Growth requirements. The growth requirements of strains unable to grow on minimal medium were assessed by the method of Holliday (1956).

Mucinase production. Mucinase activity was detected by the method of Ross (1959); $1 \%$ cetrimide was the flocculating agent.

\section{RESULTS}

Results obtained from 309 test strains are shown in table I.

\section{$O$ and $H$ Serotypes}

The differences in prevalence of serotypes between the groups of strains were not significant except with serotypes $\mathrm{O} 75$ and $\mathrm{H} 5$ which were more common amongst strains isolated from urine than amongst periurethral strains from normal subjects $(0.05>p>0.02$ for both serotypes); $55 \%$ of the smooth, typable strains from the upper tract belonged to serotype O75, but the total number of strains in this group was small and the incidence of $\mathrm{O} 75$ strains was not significantly higher amongst strains derived from the upper tract than amongst those from infections confined to the lower tract.

Serotypes O2, O4, O6, O8, O18ab and O75 were the most common serotypes amongst strains recovered from mid-stream urine and accounted for $54 \%$ of smooth, typable isolates. Only $16 \%$ of smooth, typable periurethral strains from normal subjects belonged to these six $\mathrm{O}$-serotypes and this difference was statistically significant $(0.01>p>0.001)$. Most $(82 \%)$ smooth, typable strains from the upper tract belonged to serotypes $\mathrm{O} 2, \mathrm{O} 4, \mathrm{O} 6, \mathrm{O} 8$, O18ab and 075 whereas these types were significantly less common $(44 \%)$ amongst strains from the lower tract $(0.05>p>0.02)$.

Sixty percent of $\mathrm{H}$-serotypable urinary strains and $39 \%$ of periurethral strains from normal subjects belonged to $\mathrm{H}$-serotypes $\mathrm{H} 1, \mathrm{H} 4, \mathrm{H} 5$ and $\mathrm{H} 7$; this difference was not statistically significant. An excess of particular combinations of $\mathrm{O}$ - and $\mathrm{H}$-serotypes was not found in any group of strains but most O75 strains were either non-motile or of type $\mathrm{H} 5$.

\section{$K$-antigen content}

The K-antigen titres are shown in table II. Approximately the same proportion of strains in each group had K-antigen titres of $>1024$. However, more urinary strains had titres of 32-512 (K-rich) compared with periurethral strains from normal subjects $(\mathrm{p}=0.008)$. More strains from the upper tract 


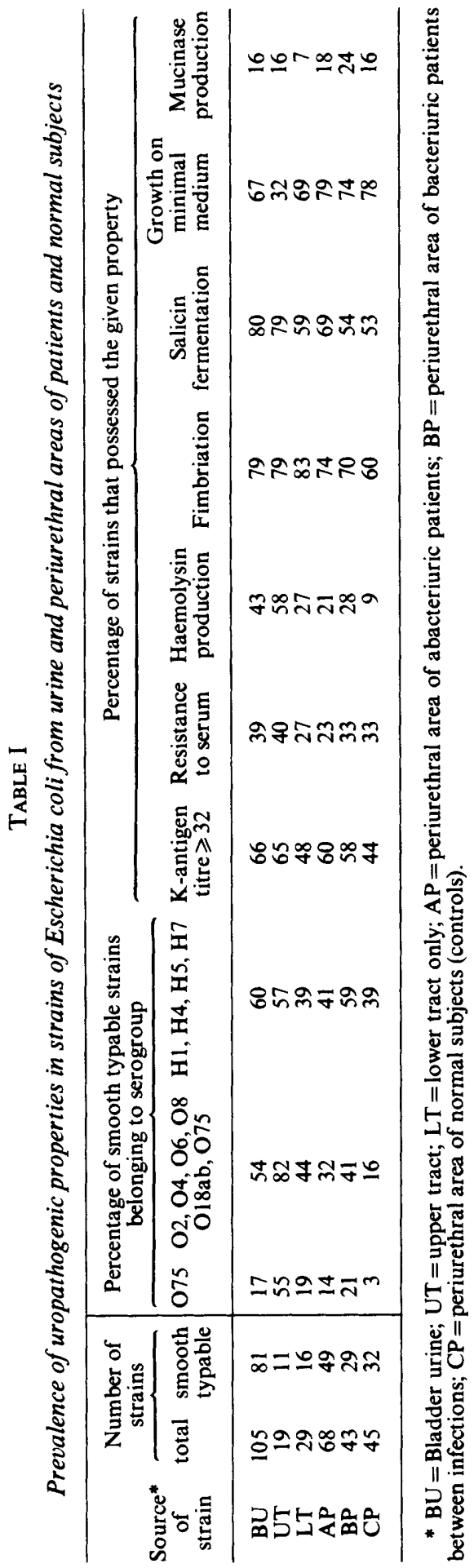


TABLE II

$K$-antigen titres of strains of Escherichia coli from urine and periurethral areas of patients and normal subjects

\begin{tabular}{|c|c|c|c|c|c|c|c|c|c|c|c|c|}
\hline \multirow{2}{*}{$\begin{array}{l}\text { Source of } \\
\text { strain* }\end{array}$} & \multicolumn{12}{|c|}{ Percentage of strains in each group with $\mathrm{K}$-antigen titres of } \\
\hline & 0 & 1 & 2 & 4 & 8 & 16 & 32 & 64 & 128 & 256 & 512 & 1024 \\
\hline BU & 28 & 2 & 2 & 0 & 1 & 1 & 1 & 10 & 9 & 21 & 14 & 11 \\
\hline UT & 26 & 0 & 0 & 5 & 1 & 5 & 5 & 0 & 11 & 16 & 11 & 21 \\
\hline LT & 48 & 0 & 0 & 0 & 0 & 4 & 0 & 0 & 17 & 17 & 10 & 4 \\
\hline$\overline{\mathrm{AP}}$ & 38 & 1 & 0 & 0 & 0 & 0 & 2 & 3 & 16 & 15 & 18 & 7 \\
\hline BP & 37 & 0 & 0 & 5 & 0 & 0 & 3 & 5 & 16 & 16 & 9 & 9 \\
\hline CP & 54 & 0 & 0 & 0 & 0 & 2 & 4 & 9 & 4 & 7 & 9 & 11 \\
\hline
\end{tabular}

* See footnote to table I.

$(64 \%)$ had $K$-antigen titres of $\geqslant 32$ than strains from the lower tract $(48 \%)$, but this difference was just outside the accepted level of statistical significance $(\mathrm{p}=0.06)$. There was no difference in $\mathrm{K}$-antigen titres between strains from the lower-tract and periurethral strains from normal subjects.

\section{Serum sensitivity}

Most rough strains $(82 \%)$ were sensitive to the bactericidal activity of serum. E. coli strains may develop rough colonies on storage and these strains were excluded from analysis. The serum sensitivity of smooth urinary strains was similar to that of periurethral strains from normal subjects. Strains from the lower tract were slightly more sensitive than those from the upper tract but this was not statistically significant. The $\mathrm{K}$-antigen content of smooth strains was not directly related to their serum sensitivity but a few strains (15) had $\mathrm{K}$-antigen titres of $<32$ and were resistant to the bactericidal activity of serum (table III). Only seven rough strains were serum resistant, of which two strains had $\mathrm{K}$-antigen titres of $<32$, but not all rough strains were devoid of $\mathrm{K}$ antigen (table III).

TABLE III

Relationship of $K$-antigen titre to serum sensitivity

\begin{tabular}{ll|cc}
\hline $\begin{array}{l}\text { Reaction } \\
\text { with serum }\end{array}$ & $\begin{array}{c}\text { Type of } \\
\text { agglutination } \\
\text { reaction }\end{array}$ & $\begin{array}{c}\text { Number of } \\
\text { K-antigen titres of } \\
\text { strains with }\end{array}$ \\
\hline Resistant & $\begin{array}{l}\text { smooth } \\
\text { rough } \\
\text { Smooth }\end{array}$ & 15 & $>1 / 32$ \\
& rough & 99 & 68 \\
& 18 & 89 \\
\hline
\end{tabular}




\section{Haemolysin production}

Most haemolytic strains produced both "liquid" and "solid" haemolysins; six strains produced only "liquid" haemolysin, but none produced only "solid" haemolysin. The number of urinary strains that were haemolytic $(43 \%)$ was significantly greater than the number of haemolytic periurethral strains from normal subjects $(\mathrm{p}<0.001)$. The majority of strains from the upper tract $(58 \%$ ) produced haemolysin compared with $27 \%$ of strains from the lower tract but this difference just failed to reach statistical significance $(0.1>p>0.05)$. The proportion of haemolytic strains amongst lower-tract strains was significantly greater than amongst periurethral strains from normal subjects $(0.02>p>0.01)$. Haemolysin production was associated with serogroups $\mathrm{O} 4$ and $\mathrm{O} 6 ; 82 \%$ of haemolytic strains belonged to serotype $\mathrm{O} 4$ and $85 \%$ of serotype $\mathrm{O} 6$ strains were haemolytic.

\section{Fimbriation}

Most strains in all groups produced fimbriae, but a significantly higher proportion of urinary strains $(79 \%)$ were fimbriate compared with periurethral strains from normal subjects $(60 \% ; 0.02>p>0.01)$. There was no difference between the proportions of fimbriate strains from the upper and lower tracts.

\section{Fermentation of sucrose, salicin and dulcitol}

There were no significant differences between strains from different sources in their ability to ferment sucrose and dulcitol but a significantly greater proportion of urinary strains $(80 \%)$ fermented salicin compared with periurethral strains from normal subjects $(53 \% ; \mathrm{p}<0.001)$. There was no difference between the fermentative abilities of strains from the upper and lower tracts.

\section{Sensitivity to serine, spermine and urea}

The mean MICs of serine, spermine and urea were almost identical for each group. Reducing the $p \mathrm{H}$ of the medium resulted in an increase in the mean MIC of serine and almost total abolition of the antibacterial activity of spermine (fig. 1). In general, strains were more sensitive to urea at the lower $p \mathrm{H}$, but a few strains were not affected by $p \mathrm{H}$ changes (fig. 2).

\section{Growth requirements of strains}

Significantly fewer strains from the upper tract $(32 \%)$ grew on unsupplemented minimal medium compared with strains from the lower tract $(69 \%$; $0.05>p>0.02$ ). There were no other significant differences between the groups. Strains unable to grow on minimal medium varied in nutritional requirements; a few failed to grow on any of the supplemented plates. 


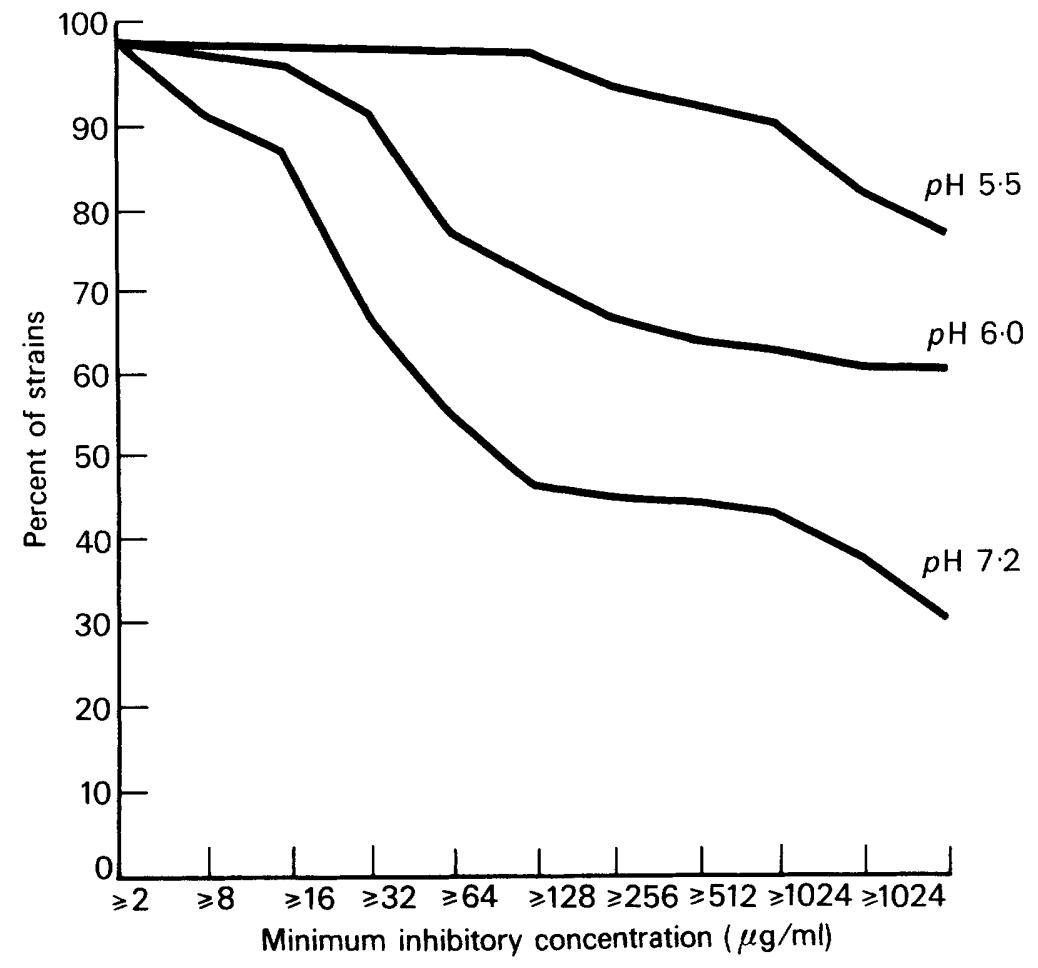

FIG. 1.-Effect of $p \mathrm{H}$ on the inhibition of Escherichia coli by serine.

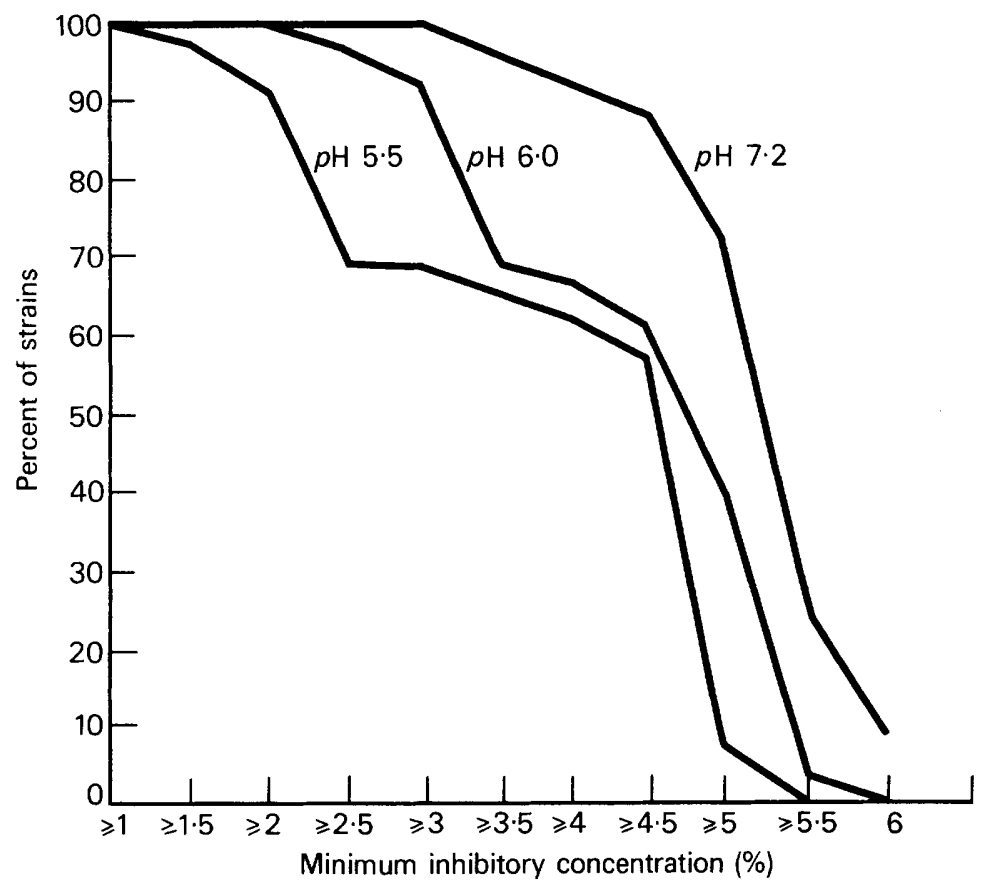

FIG. 2.-Effect of $p \mathrm{H}$ on the inhibition of Escherichia coli by urea. 


\section{Mucinase production}

Mucinase was not detected in most strains. There was no correlation between the mucinase titres of periurethral strains and the degree of colonisation as reflected in the number of colonies recovered from the periurethral swabs.

\section{Combinations of uropathogenic properties}

Five properties were significantly more common amongst urinary strains than amongst periurethral strains from normal subjects. Strains were awarded a score of 1 for each of the following properties: (i) O-serotypes 2, 4, 6, 8 , 18ab or 75 ; (ii) $\mathrm{K}$-antigen titre $>32$; (iii) haemolysin production; (iv) fimbriation; (v) salicin fermentation. The results are shown in table IV. Urinary strains had significantly higher scores than periurethral strains from bacteriuric patients between infections $(p=0.0018)$, abacteriuric patients $(\mathrm{p}=0.0018)$ and normal subjects $(\mathrm{p}=<0.001)$. Periurethral strains from bacteriuric patients between infections were not significantly different from those from abacteriuric patients but strains from both groups had significantly higher scores than those from normal subjects $(p<0.001)$. The exclusion of periurethral strains from bacteriuric patients which subsequently gave rise to infection did not significantly alter the mean score for that group. Periurethral strains from patients with the "urethral syndrome" did not differ from those recovered from asymptomatic, abacteriuric patients. Strains from the upper tract had significantly higher scores than strains from the lower tract $(p=0.03)$ and strains from the lower tract had significantly higher scores than periurethral strains from normal subjects $(\mathrm{p}=0 \cdot 006)$.

\section{DISCUSSION}

Five of the potentially uropathogenic properties of $E$. coli that we examined were more common amongst strains from urinary infections and significantly

TABLE IV

Prevalence of combined uropathogenic properties in strains of Escherichia coli from urine and from periurethral areas of patients and normal subjects

\begin{tabular}{|c|c|c|c|c|c|c|}
\hline \multirow{2}{*}{$\begin{array}{l}\text { Source of } \\
\text { strains }\end{array}$} & \multirow{2}{*}{$\begin{array}{l}\text { Number of } \\
\text { strains }\end{array}$} & \multicolumn{5}{|c|}{$\begin{array}{l}\text { Percentage of strains with a } \\
\text { scoret of }\end{array}$} \\
\hline & & $>1$ & $>2$ & $>3$ & $>4$ & $>5$ \\
\hline $\mathrm{BU}$ & 105 & 99 & 86 & 65 & 43 & 16 \\
\hline UT & 19 & 100 & 84 & 68 & 47 & 21 \\
\hline LT & 29 & 93 & 83 & 48.5 & 14 & 7 \\
\hline AP & 68 & 96 & 81 & 43 & 21 & 8 \\
\hline BP & 43 & 98 & 70 & 36 & 24 & 12 \\
\hline $\mathrm{CP}$ & 45 & 89 & 53 & 22 & 11 & 2 \\
\hline
\end{tabular}

* See footnote to table I.

† See text. 
less common amongst periurethral strains from normal subjects. These were: (1) O-serotypes 2, 4, 6, 8, 18ab and 75, (2) high K-antigen titre, (3) haemolysin production, (4) production of fimbriae, (5) salicin fermentation. Some of these properties may confer resistance to host defence mechanisms; possession of $\mathrm{K}$-antigen confers resistance to phagocytosis, antibody binding and killing by complement, and the degree of resistance depends upon the amount of antigen (Glynn and Howard, 1970; Howard and Glynn, 1971). In the present study, the high incidence of $\mathrm{K}$-rich urinary strains suggests that this property is important in the pathogenicity of $E$. coli, but we were unable to confirm the relationship between serum-resistance and $\mathrm{K}$-antigen content observed by Howard and Glynn (1971). Moreover, we did not find that this property influenced the localisation of infection, although Glynn, Brumfitt and Howard (1971) found that patients with renal infection were usually infected with $\mathrm{K}$-rich strains whereas patients with lower tract infection were not.

The prevalence of haemolytic strains in urinary infections suggests that haemolysin production is related to the ability to invade and infect the urinary tract. A correlation was also observed between haemolysin production and localisation of infection and it seems likely that haemolytic strains are selected during ascending invasion of the urinary tract. This supports the hypothesis that haemolytic strains have a superior ability to infect the kidney, possibly due to the inhibitory effect of free haemoglobin on the serum bactericidal system (Bullen and Rogers, 1969)

Eden et al. (1978) suggested that fimbriae enable $E$. coli to adhere to the epithelial cells lining the urinary tract and that fimbriate strains might resist removal by hydrokinetic clearance. Fimbriate strains were isolated frequently from urinary infections in the present study, but the relationship between fimbriation and uropathogenicity was not strong because fimbriae could not be demonstrated in $21 \%$ of urinary isolates.

The observed correlations of pathogenicity with O-serotype and salicin fermentation are less readily explained in terms of resistance to host defence mechanisms. Although six O-serotypes $(\mathrm{O} 2, \mathrm{O} 4, \mathrm{O} 6, \mathrm{O} 8, \mathrm{O} 18 \mathrm{ab}$ and $\mathrm{O} 75)$ were responsible for the majority of urinary infections, a considerable proportion were due to other O-serotypes. Other authors (Vosti, Goldberg and Rantz, 1965; Grüneberg, Leigh and Brumfitt, 1968; Ganguli, 1970; Dootson, Maclaren and Titcombe, 1973) have reported similar findings, but different $\mathrm{O}$-serotypes have been predominant in the various series. The prevalence of O-serotypes 4 and 6 amongst urinary strains may be related to haemolysin production. Most of our strains that belonged to serotypes $\mathrm{O} 4$ and $\mathrm{O} 6$ were haemolytic and this association has been reported by several other authors (Vahlne, 1945; Sjöstedt, 1946; Cooke and Ewins, 1975).

McCabe and Jackson (1960) observed that strains from patients with pyelonephritis often failed to ferment sucrose and salicin, but most of our urinary strains fermented salicin. We were unable to demonstrate any difference in the fermentative abilities of strains recovered from the upper and lower tracts and the reported relationship between fermentation of certain sugars and ability to cause urinary infection may be fortuitous. 
Previous workers had suggested that serum resistance, mucinase production and ability to grow in the presence of serine, spermine and urea were related to uropathogenicity but these properties were not more common in our urinary strains. The decrease in inhibitory activity of spermine and serine at low $p \mathrm{H}$ indicates that these components of normal urine have little inhibitory activity in vivo. However, urea was more inhibitory at low $p \mathrm{H}$. The conditions of low $p \mathrm{H}$ and high urea content in urine at night may inhibit bacterial growth at a time when hydrokinetic clearance is minimal.

Our observations on strains from human infections contrast with those of Guze et al. (1973) who correlated virulence of $E$. coli for the mouse kidney with ability to multiply in minimal medium; many of our strains from upper-tract infections were unable to grow on minimal medium. Similarly there was little correlation between $\mathrm{H}$-serotype and site of isolation; the excess of $\mathrm{H} 5$ strains in urinary infections probably reflects the prevalence of $\mathrm{O} 75$ strains.

The relationship between ability to cause infection and possession of any one of the five properties that were more common in urinary strains was not particularly strong. However, the possibility that pathogenicity is a multifactorial phenomenon was examined with a scoring system that gave each property equal weight. Strains with high scores for the combined properties were common amongst urinary isolates and rare amongst periurethral isolates from normal subjects. This indicates that strains rich in the combination of these pathogenic properties possess a greater ability to invade the urinary tract. However, strains poor in the combination of pathogenic properties are not necessarily harmless commensals; more than half of the urinary strains possessed fewer than four of the properties. This may reflect the state of the host defence mechanisms; infection with strains of low pathogenicity might occur when host defences are compromised. The localisation of infection also appears to be influenced by the properties of the infecting organism. Strains from upper-tract infections had higher scores for the combination of pathogenic properties than strains confined to the lower tract. It was noticeable that bacteriuric patients between episodes of infection were more of ten colonised by strains rich in pathogenic properties than were normal subjects, although the majority of these strains did not give rise to infection. These strains may have been the colonising strains of a previous infection or may have been seeded onto the periurethral area during a previous infection and persisted after the infection was eliminated.

\section{SUMMARY}

Properties of Escherichia coli considered to be important in the pathogenesis of urinary-tract infection were investigated. The following properties were more common in $E$. coli strains isolated from urinary infections than in periurethral strains from healthy individuals: (i) $O$ serogroups $2,4,6,8$, 18ab and 75; (ii) high $\mathrm{K}$-antigen titre; (iii) production of haemolysin; (iv) production of fimbriae; (v) fermentation of salicin. The correlation between isolation of a strain from the urinary tract and possession of any single property was not 
strong; however, strains rich in a combination of these pathogenic properties were rarely isolated from the periurethral area of healthy subjects but were common in urinary infections. Nevertheless, a significant proportion of urinary strains had few pathogenic properties. Strains rich in pathogenic properties were more commonly isolated from upper urinary-tract infections than from lower-tract infections; this indicates that the properties of the invading organism may influence the localisation of infection.

\section{REFERENCES}

Bettelheim, K. A. And Taylor, J. 1969. A study of Escherichia coli isolated from chronic urinary infection. J. med. Microbiol., 2, 225.

Bullen, J. J. AND Rogers, H. J. 1969. Bacterial iron metabolism and immunity to Pasteurella septica and Escherichia coli. Nature, 224, 380.

Cattell, W. R., McSherry, M. A., Northeast, A., Powell, E., Brooks, H. J. L. and O'Grady, F. 1974. Periurethral enterobacterial carriage in pathogenesis of recurrent urinary infection. Brit. med. J., 4, 136.

Chandler, M. E. And Bettelheim, K. A. 1974. A rapid method of identifying Escherichia coli H antigens. Zentbl. Bakt. ParasitKde, I. Abt. Orig., 229, 74.

COOKE, E.M. 1968. Properties of strains of Escherichia coli isolated from the faeces of patients with ulcerative colitis, patients with acute diarrhoea and normal persons. J. Path. Bact., 95, 101.

CoOKe, E.M. AND EwINS, S.P. 1975. Properties of strains of Escherichia coli isolated from a variety of sources. J. med. Microbiol., 8, 107.

Davis, B.D. AND MiNGIOLI, E.S. 1950. Mutants of Escherichia coli requiring methionine or vitamin $\mathrm{B}_{12}$. J. Bact., 60, 17.

Dootson, P.H., Maclaren, D.M. AND Titcombe, D.H.M. 1973. The distribution of urinary O-groups of Escherichia coli in urinary infections and in the normal flora. In Urinary tract infection. Proceedings of 2nd National Symposium, March 1972, edited by W. Brumfitt, and W. W. Asscher. Oxford University Press: London, p. 33.

Duguid, J. P. 1968. The function of bacterial fimbriae. Archvm. Immun. Ther. exp., 16, 173.

Duguid, J. P., Smith, I. W., Dempster, G. ANd Edmunds, P. N. 1955 . Non-flagellar filamentous appendages (fimbriae) and haemagglutinating activity in Bacterium coli. J. Path. Bact., 70, 335.

EDEN, C. S. 1978. Attachment of Escherichia coli to human urinary tract epithelial cells. In vitro test system applied to a study of urinary-tract infections. Scand. J. infect. Dis., suppl. 15, 5.

EDWARDS, P. R. AND EWING, W. H. 1972. The genus Escherichia. In Identification of Enterobacteriaceae, 3rd ed. Burgess: Minneapolis, p. 70.

GANGULI, L. 1970. Serological grouping of Escherichia coli, in bacteriuria of pregnancy. $J$. med. Microbiol., 3, 201.

GLYNN, A. A. AND HowARD, C. J. 1970. The sensitivity to complement of strains of Escherichia coli related to their $\mathrm{K}$. antigens. Immunology, 18, 331 .

GlynN, A. A., BRUmfitT, W. AND Howard, C. J. 1971. K antigens of Escherichia coli and renal involvement in urinary-tract infections. Lancet 1, 514.

GRÜNEBERG, R. N., LEIGH, D. A. AND BRUMFITT, W. 1968. Escherichia coli serotypes in urinary tract infection. Studies in domiciliary, ante-natal and hospital practice. In Urinary tract infection. Proceedings of 1st National Symposium, April, 1968, edited by F. O'Grady and W. Brumfitt. Oxford University Press: London, p. 68.

Guze, L. B., Montgomerie, J. Z., Potter, C. S. and Kalmanson, G. M. 1973. Pyelonephritis. XVI. Correlates of parasite virulence in acute ascending Escherichia coli pyelonephritis in mice undergoing diuresis. Yale J. Biol. Med., 46, 203.

Holliday, R. 1956. A new method for the identification of biochemical mutants of microorganisms. Nature, Lond., 178, 987. 
Howard, C. J. AND GlYNN, A. A. 1971. The virulence for mice of strains of Escherichia coli related to the effects of $\mathrm{K}$ antigens on their resistance to phagocytosis and killing by complement. Immunology, $20,767$.

MCCABE, W. R. AND JACKSON, G. G. 1960. The natural course of retrograde infections of the urinary tract of rats with different serotypes of Escherichia coli or enterococcus. In Biology of pyelonephritis, edited by E. H. Kass and E. Quinn. Little Brown: Boston, p. 39.

Miles, A. A., Misra, S. S. ANd Irwin, J. O. 1938. The estimation of the bactericidal power of the blood. J. Hyg., Lond., 38, 732.

O'Grady, F. W., McSherry, M. A., Richards, B., O'Farrell, S. M. and Cattell, W. R. 1970. Introital enterobacteria, urinary infection and the urethral syndrome. Lancet, 2 , 1208.

Ross, C. A. C. 1959. Mucinase activity of intestinal organisms. J. Path. Bact., 77, 642.

Shand, D. G., Mackenzie, J. C., Cattell, W. R. and Cato, J. 1968. Estimation of residual urine volume with ${ }^{131}$ I-hippuran. Brit. J. Urol., 40, 196.

SuöstedT, S. 1946. Pathogenicity of certain serological types of B. coli. Acta path. microbiol. scand., suppl. 63.

Stamey, T. A., Govan, D. E. And Palmer, J. M. 1965. The localisation and treatment of urinary tract infections: the role of bactericidal urine levels as opposed to serum levels. Medicine, Baltimore, 44, 1.

TAYlor, P. W., Roberts, A. P. AND Gower, P. E. 1972. Evaluation of a technique for the estimation of serum bactericidal activity against gram-negative organisms. Med. lab. Tech., 29, 272.

VAHLNE, G. 1945. Serological typing of the colon bacteria. Acta path. microbiol. scand., suppl. 62.

Vosti, K. L., Goldberg, L. M. AND Rantz, L. A. 1965. Host-parasite interaction among infections caused by Escherichia coli. In Progress in pyelonephritis, edited by E. H. Kass. Davis: Philadelphia, p. 103. 